\title{
Sero-prevalence of hepatitis B and C viral infections in Ghanaian HIV positive cohort: a consideration for their health care
}

\author{
Faustina Pappoe $^{1 *}$ D, Charles Kofi Oheneba Hagan², Dorcas Obiri-Yeboah ${ }^{1}$ and Paul Nsiah ${ }^{3}$
}

\begin{abstract}
Background: Antiretroviral therapy (ART) has significantly decreased HIV/AIDS-related morbidity and mortality. However, globally, many people living with HIV die from non-AIDS related illnesses including liver diseases which occur partly due to co-infection with HBV and or HCV. The aim of this study was to determine the seroprevalence of HBV and HCV among HIV infected individuals receiving care from three different hospitals in the Central Region of Ghana.

Methods: This research was a case-case study. The population consisted of ART naive persons (newly confirmed HIV cases) and those who had been on ART for more than 3 months (old cases). Each individual's sociodemographic characteristics and clinical data including their HBV and HCV status were collected. Those who knew their HBV and HCV status and those who did not know their status were tested for circulating HBsAg and anti-HCV using rapid diagnostic test cassettes. Descriptive analysis was done, and the data presented as median with interquartile range, frequency and percentage. Fisher's exact test and Pearson Chi-square $\left(x^{2}\right)$ test were used to determine associations between categorical variables.
\end{abstract}

Results: Overall, 394 HIV individuals aged, 3 to 76 years old with a median age of 41 (IQR:34-49) participated in this study. Circulating HBsAg and anti-HCV were detected in 6.1\% (24/394) and 0.5\% (2/393) participants respectively with an overall seroprevalence of 6.6\% (26/394). None of the participants was positive for both HBV and HCV infections. 92.1\% (363/394) had no information on their HBV status while all the 394 participants did not know their HCV status during data collection. No significant association of HBV infection rate was found in all the socio-demographic data of the participants. But HBV infection rates were significantly higher in those at WHO clinical stages 2 and $3(P=0.004)$.

Conclusion: HBV and HCV were detected among the HIV-infected participants. Majority of the participants had no information on their HBV status and none of the participants had information on his or her HCV status. This study recommends the need for policy makers to provide free HBV and HCV screening for all HIV infected individuals for their effective management.

Keywords: HIV, HBV, HCV, Co-infection, Seroprevalence, Ghana

\footnotetext{
* Correspondence: f.pappoe@uccsms.edu.gh; zizalai@yahoo.com

${ }^{1}$ Department of Microbiology and Immunology, School of Medical Sciences, College of Health and Allied Sciences, University of Cape Coast, Cape Coast, Ghana

Full list of author information is available at the end of the article
}

(c) The Author(s). 2019 Open Access This article is distributed under the terms of the Creative Commons Attribution 4.0 International License (http://creativecommons.org/licenses/by/4.0/), which permits unrestricted use, distribution, and reproduction in any medium, provided you give appropriate credit to the original author(s) and the source, provide a link to the Creative Commons license, and indicate if changes were made. The Creative Commons Public Domain Dedication waiver (http://creativecommons.org/publicdomain/zero/1.0/) applies to the data made available in this article, unless otherwise stated. 


\section{Background}

The blood borne pathogens, Human Immunodeficiency Virus (HIV), Hepatitis B Virus (HBV), and Hepatitis C Virus $(\mathrm{HCV})$ are still a significant worldwide public health challenge [1, 2]. Globally, it is estimated that almost 37 million people are infected or living with HIV and approximately two thirds of the infected individuals live in Sub-Saharan Africa [1]; more than 250 million and 70 million people are also estimated to be chronically infected with $\mathrm{HBV}$ and $\mathrm{HCV}$, respectively [2]. In 2017 , it was estimated that 940,000 deaths of the world's HIV infected populations occurred due to AIDS-related illnesses [1]. The introduction of antiretroviral therapy (ART) has significantly decreased HIV/AIDS-related morbidity and mortality [3]. However, deaths resulting from non-AIDS-related illnesses have been on the increase. Worldwide, a large number of people living with HIV (PLHIV) die from non-AIDS illnesses including liver diseases [4]. The increased morbidity and mortality associated with liver diseases among PLHIV is partly due to co-infection with HBV and or HCV [2] and partly due to non-infectious agents. Thus, the global prevalence of HBV and HCV among PLHIV is 7.4 and 1.0\% respectively [2].

Co-infection of HIV with viral hepatitis (HBV and/or $\mathrm{HCV}$ ) occurs commonly because these viral infections share similar mode of transmission [5-7]. Both HBV and $\mathrm{HCV}$ are hepatotrophic viruses that account for $96 \%$ of all hepatitis mortality. They cause severe morbidity including cirrhosis and hepatocellular carcinoma (HCC) due to intra-hepatic apoptosis and mortality particularly among HIV-infected individuals [2, 8, 9]. The World Health Organization (WHO) recommends that all PLHIV including children regardless of their CD4 counts should initiate ART [10]. Those who are co-infected with chronic HBV irrespective of their alanine aminotransferase (ALT) level, hepatitis B e antigen (HBeAg) status or HBV DNA levels should have tenofovir disoproxil fumarate (TDF) in their ART regimen since it is active against HBV. Those co-infected with HCV should also be provided with direct-acting antiviral (DAA) drug which has been shown to have lesser drug-drug interactions with antiretroviral drugs compared to the older $\mathrm{HCV}$ regimen containing pegylated interferon and ribavirin $[10,11]$. This treatment guideline is adopted in the Ghanaian setting where the patients are frequently monitored for liver fibrosis using aspartate aminotransferase (AST), alanine aminotransferase (ALT), aminotransferase/platelet ratio index (APRI) and all parameters of the liver function test every 6 months [12]. The purpose of this guideline is to help decrease liver-related morbidities and mortalities associated with HBV and or HCV co-infection [10]. Hence, knowledge on HBV and HCV status of PLHIV is vital for their effective management. However, in Ghana although HIV,
HBV and HCV are public health issues, free HBV and $\mathrm{HCV}$ laboratory testing and treatment are not provided side-by-side HIV testing and treatment due to lack of resources and this might have negative effect on the efficacy of the regimens used to manage them. In Ghana, the estimated HIV prevalence is $1.47 \%$, and that of HBV and $\mathrm{HCV}$ reported in the general population are 5.5-15.8\% and $0.4-8.4 \%$ respectively [13-19]. However, studies on $\mathrm{HBV}$ and $\mathrm{HCV}$ among $\mathrm{HIV}$ infected individuals are limited and most of these studies were done at a single site, with HBV prevalence ranging from 2.4 to $41.7 \%$ while $1.0 \%$ has been reported for HCV $[20,21]$. This study was a multi-centered one that aimed to determine the prevalence of HBV and HCV among HIV infected persons who were receiving care from three different hospitals in the Central Region of Ghana.

\section{Methods}

\section{Study design, area and population}

This study was a subset of a parent case-case study conducted on toxoplasmosis among HIV infected individuals from May to August 2015. The participants were recruited from three hospitals in the Central Region. The hospitals were the Cape Coast Teaching Hospital $(\mathrm{CCTH})$ which is the referral and teaching hospital in the Central Region, Cape Coast Metropolitan Hospital $(\mathrm{CCMH})$ both located in Cape Coast Metropolis and Saltpond Municipal Hospital (SMH) located in the Mfantseman District. All these hospitals provide services to HIV infected individuals within and beyond the Central Region. $\mathrm{CCTH}$ and $\mathrm{SMH}$ receive the highest number of infected individuals. CCTH is a tertiary facility with about 400 beds. The HIV/STIs clinic in the facility was the first to be established in the region in 2006 and has registered over 4000 HIV positive patients since. SMH has 112 beds and provides service to 517 HIV infected patients while CCMH has 120 beds with an estimated 365 HIV population.

\section{Sampling}

A total of 394 HIV infected in-patients and out-patients of all age groups including children who were attending clinics at $\mathrm{CCTH}, \mathrm{CCMH}$ and $\mathrm{SMH}$ in the Central Region were consecutively enrolled. The participants were of two sets: antiretroviral therapy (ART) naive individuals (newly confirmed HIV cases) and those who had been on ART for more than 3 months (old cases). The socio-demographic characteristics, clinical data including their WHO HIV clinical stage 1, 2, 3 or 4 and comorbid conditions including their $\mathrm{HBV}$ and $\mathrm{HCV}$ status were collected. The data were obtained from the patients or guardians through structured and standardized questionnaire interview, medical examination records, and informants including physician or medical personnel. Venous 
blood samples (2-5 mL) were drawn into sterile sodium citrate tubes and centrifuged at $2500 \mathrm{x}$ g for $10 \mathrm{~min}$. The plasma was collected in Eppendorf tubes and stored at $-80{ }^{\circ} \mathrm{C}$ until tested. Those who knew their HBV and $\mathrm{HCV}$ status and those who did not know their status were both tested.

\section{Serology}

Screening of the participants for circulating hepatitis B surface antigen (HBsAg) and anti-HCV was done using rapid diagnostic test cassettes (Innovita Biological Technology Co. Ltd., Beijing China). Testing was done following the manufacturer's protocol. Briefly, a drop of the plasma was transferred into the sample well $(S)$ and the result was read within 10 to $15 \mathrm{~min}$. The result was considered positive when two purple bands appeared at both the control line $(\mathrm{C})$ and the test line $(\mathrm{T})$, and negative when only one colour band was observed at the control line $(\mathrm{C})$. The sensitivity and specificity for the test kits were 98 and $>99 \%$ respectively for both HBsAg and anti-HCV test kits.

\section{Statistical analysis}

The collected data were analyzed using SPSS version 16.0 (Chicago, SPSS Inc.). Descriptive analysis was done to determine median with interquartile range, frequency and percentage of the variables of the participants. Fisher's exact test and Pearson Chi-square were used to assess the differences in the proportions of $\mathrm{HBsAg}$ positivity between categorical variables. $P$ value $\leq 0.05$ was considered statistically significant.

\section{Results}

\section{The sociodemographic and clinical data of the} participants

For the 394 HIV-infected patients who participated in this study, majority was recruited from $\mathrm{CCTH}$ 217(55.1\%) followed by SMH 149(37.8\%) with the lowest proportion $28(7.1 \%)$ obtained from CCMH (Table 1). In total, there was a wide range of ages among the participants, namely 3 to 76 years old with median age of 41 years with IQR of 49-34 years and there were fewer males than females, thus, 96(24.37\%) males and $298(75.63 \%)$ females. In terms of educational status, most of the participants had attained basic education $[257(65.2 \%)]$, few had attained secondary education [42(10.7\%)] and fewer had attained tertiary education [18(5.6\%)] while close to fifth few had never been to school [77(19.5\%)]. Occupationally, majority of the participants were unemployed [300(76.1\%)]; few were employed in the informal sector of the economy $[63(16.0 \%)]$ and less than a tenth were employed in the formal sector $[31(8 \%)]$. The marital status of the participants was varied, ranging from married/cohabiting
[218(55.3\%)], single [63(16.0\%)], divorced [60(15.2\%)] to widow/widower [53(13.5\%)] in decreasing order of magnitude. Those who were residents of rural areas constituted the highest proportion [266(67.5\%)].

With regards to clinical data, of the 394 participants, approximately $47(12 \%)$ were newly infected HIV ART naïve individuals while the rest [347(88.1\%)] were old cases (Table 2). They included 271(68.8\%) WHO stage 1 , $78(19.8 \%)$ stage 2, 29(7.4\%) stage 3 and 16(4.1\%) stage 4 infected individuals. Nevertheless, extremely high proportion $363(92.1 \%)$ of the participants had no information on their HBV status coupled with the fact that none of the participants had information on his/her HCV status when the data were collected.

\section{HBV and HCV seroprevalence among the participants}

Circulating HBsAg and anti- HCV were detected in 24 and 2 respectively of the 394 participants with an overall seroprevalence of 26/394(6.6\%) (Table 3). None of the participants was positive for both $\mathrm{HBV}$ and $\mathrm{HCV}$ infections (Table 3). The $24 \mathrm{HBV}$ positive individuals included 5/24(21\%) already known HBV positive patients who also tested positive when tested again in this study while the remaining 19/24(79.2\%) were part of those who had no information on their HBV status (92.1\%; Table 2). With regards to seroprevalence in relation to the patient's data, HBV was detected in nearly all the age groups. The lowest $1(2.3 \%)$ and highest $11(9.3 \%)$ positive rate were detected in the participants within the age groups 20-29 and 30-39 years respectively. Infection in females $[19(6.4 \%)]$ was higher than in males [5(5.2\%)]. Moreover, the positive rate was higher among those who had never been to school [5(6.5\%)] and those who had attained basic education [17(6.6\%)]. Approximately $2(5 \%)$ of those who had attained secondary education was positive for HBsAg whereas no infection was detected among those with tertiary education background (Table 3). Also, 20 (6.7\%) was observed among those with informal jobs which was higher than that in those who were unemployed [3(4.7\%)] and those with formal employment [1(3.2\%)]. In relation to the marital status, divorced participants had the highest positive rate [5(8.3\%)] followed by married/cohabiting [16(7.3\%)], single $[2(3.2 \%)]$ and the widow/widower $[1(1.9 \%)]$. Those who were living in rural areas had a slightly higher positive rate $[17(6.4 \%)]$ compared to those in the urban areas $[7(5.5 \%)]$. The differences in the positive rates within each of the variables under investigation in this study were observed not to be statistically significant (Table 3).

In addition, the positive rate of $\mathrm{HBV}$ was higher among the HIV old cases [23(6.6\%)] than the newly diagnosed cases [1(2.1\%)] but this difference was not significant $(P=0.376)$. Also, slightly more than $12(15 \%)$ of WHO stage 2 patients were infected with HBV followed 
Table 1 Socio-demographic characteristics of the participants enrolled in this study

\begin{tabular}{|c|c|c|c|c|}
\hline Variables & $\begin{array}{l}\text { CCTH } \\
n=217(55.1 \%)\end{array}$ & $\begin{array}{l}\text { CCMH } \\
n=28(7.1 \%)\end{array}$ & $\begin{array}{l}\text { SMH } \\
n=149(37.8 \%)\end{array}$ & $\begin{array}{l}\text { Total } \\
\text { N (\%) }\end{array}$ \\
\hline \multicolumn{5}{|l|}{ Age (years) } \\
\hline$\leq 19$ & $6(2.8)$ & $1(3.6)$ & $5(3.4)$ & $12(3.1)$ \\
\hline $20-29$ & $21(9.7)$ & $8(28.6)$ & $15(10.1)$ & $44(11.2)$ \\
\hline $30-39$ & $61(28.1)$ & $6(21.4)$ & $51(34.2)$ & $118(30.0)$ \\
\hline $40-49$ & $76(35.0)$ & $8(28.6)$ & $41(27.5)$ & $125(31.7)$ \\
\hline $50-59$ & $42(19.4)$ & $4(14.3)$ & $25(16.8)$ & $71(18.0)$ \\
\hline$\geq 60$ & $11(5.1)$ & $1(3.6)$ & $12(8.1)$ & $24(6.1)$ \\
\hline Median (IQR) & $42(34.5-49)$ & $36(26.7-543)$ & $41(35-49.5)$ & $41(34-49)$ \\
\hline \multicolumn{5}{|l|}{ Gender } \\
\hline Male & 49 (22.6) & $4(14.3)$ & $43(28.9)$ & $96(24.4)$ \\
\hline Female & $168(77.4)$ & $24(85.7)$ & $106(71.1)$ & $298(75.6)$ \\
\hline \multicolumn{5}{|l|}{ Educational status } \\
\hline None & $46(21.2)$ & $5(17.9)$ & $26(17.4)$ & $77(19.5)$ \\
\hline Basic & $136(62.7)$ & $17(60.7)$ & $104(69.8)$ & $257(65.2)$ \\
\hline Secondary & $23(10.6)$ & $6(21.4)$ & $13(8.7)$ & $42(10.7)$ \\
\hline Tertiary & $12(5.5)$ & $0(0.0)$ & $6(4.0)$ & $18(5.6)$ \\
\hline \multicolumn{5}{|l|}{ Employment } \\
\hline Unemployed & $35(16.1)$ & $5(17.9)$ & $23(15.4)$ & $63(16.0)$ \\
\hline informal & $163(75.1)$ & 22 (78.6) & $115(77.2)$ & $300(76.1)$ \\
\hline formal & $19(8.8)$ & $1(3.6)$ & $11(7.4)$ & $31(7.9)$ \\
\hline \multicolumn{5}{|l|}{ Marital status } \\
\hline Single & $36(16.6)$ & $6(21.4)$ & $21(14.1)$ & $63(16.0)$ \\
\hline Married/Cohabiting & $121(55.8)$ & $19(67.9)$ & $78(52.4)$ & $218(55.3)$ \\
\hline Widow/widower & $32(14.8)$ & $1(3.6)$ & $20(13.4)$ & $53(13.5)$ \\
\hline Divorced & 28 (12.9) & $2(7.1)$ & $30(20.1)$ & $60(15.2)$ \\
\hline \multicolumn{5}{|l|}{ Residence } \\
\hline Rural & $147(67.7)$ & 19 (67.9) & $100(67.1)$ & $266(67.5)$ \\
\hline Urban & 70 (32.3) & $9(32.1)$ & 49 (32.9) & $128(32.5)$ \\
\hline
\end{tabular}

by stage $3[2(6.9 \%)]$, stage $1[10(3.7 \%)]$ and finally none of the stage 4 patients was infected. This difference was found to be statistically significant $(P=0.004)$.

The individuals $[2(0.5 \%)]$ who were positive to anti-HCV belonged to age groups 30-39 and 40-49 years and were all females (Table 3 ). HCV infection was detected only among those with secondary education $[1(2.4 \%)]$ and those who had never been to school [1(1.3\%)]. Also, the infected persons were among those who were unemployed [1(1.6\%)] and had informal employment $[1(0.3 \%)]$, married/cohabiting [2(0.9\%)], living in rural areas $[2(0.8 \%)]$, belonged to HIV old case group $[2(0.6 \%)]$ and WHO clinical stages $2[1(1.3 \%)]$ and 4 [1(6.3\%)]. No statistical tests for association of infection rates in the groups was assessed due to the limited number of positivity.

\section{Discussion}

People living with HIV have a greater risk of being co-infected with $\mathrm{HBV}$ and or $\mathrm{HCV}$ compared to the general population because these infections share a common mode of acquisition [5, 15-18, 20]. In Ghana, data on investigating simultaneously the prevalence of both HIV-HBV and HIV-HCV co-infection remain limited. This study aimed at determining the prevalence of HBV and or HCV co-infection among HIV infected persons from three different hospitals in the Central Region of Ghana. This study reports an overall viral hepatitis seroprevalence of $6.6 \%(26 / 394)$ : Twenty-four or $6.1 \%$ of the participants were HIV-HBV co-infected (i.e. had current infection) while only 2 or $0.5 \%$ were HIV-HCV co-infected (i.e. had current/past infection) with no person co-infected with both hepatitis viruses. The prevalence of HIV-HBV co-infection in this study is slightly 
Table 2 Clinical characteristics of the participants

\begin{tabular}{|c|c|c|c|c|}
\hline Variables & $\begin{array}{l}\text { CCTH } \\
n=217(55.1 \%)\end{array}$ & $\begin{array}{l}\text { CCMH } \\
n=28(7.1 \%)\end{array}$ & $\begin{array}{l}\text { SMH } \\
n=149 \text { (37.8\%) }\end{array}$ & $\begin{array}{l}\text { Total } \\
\text { N (\%) }\end{array}$ \\
\hline \multicolumn{5}{|l|}{ HIV patients } \\
\hline Newly confirmed cases & $29(13.4)$ & $7(25.0)$ & $11(7.4)$ & $47(11.9)$ \\
\hline Old cases & $188(86.6)$ & $21(75.0)$ & $138(92.6)$ & $347(88.1)$ \\
\hline \multicolumn{5}{|l|}{ WHO clinical stage } \\
\hline Stage 1 & $137(63.1)$ & $20((71.4)$ & $114(76.5)$ & $271(68.8)$ \\
\hline Stage 2 & $52(24.0)$ & $4(14.3)$ & $22(14.8)$ & $78(19.8)$ \\
\hline Stage 3 & $21(9.7)$ & $1(3.6)$ & $7(4.7)$ & $29(7.4)$ \\
\hline Stage 4 & $7(3.2)$ & $3(10.7)$ & $6(4.0)$ & $16(4.1)$ \\
\hline \multicolumn{5}{|c|}{$\mathrm{HBV} / \mathrm{HCV}$ status before testing } \\
\hline HBV known & $19\left[4^{*}\right](21.1)$ & $0(0)$ & $12(P=1 ; 8.3)$ & $31(7.9)$ \\
\hline HBV unknown & $198(91.2)$ & $28(100)$ & $137(91.9)$ & $363(92.1)$ \\
\hline HCV unknown & $217(100)$ & $28(100)$ & $149(100)$ & $394(100)$ \\
\hline
\end{tabular}

$\mathrm{P}=\left[{ }^{*}\right]=$ number of positive case $(\mathrm{s})$

low compared to most previous reports on HBV-HIV co-infection from other regions of Ghana between 1999 and $2016(8.3-41.7 \%)$ [20] (with the exception of one study that reported lower seroprevalence of $2.4 \%$ [20]) and other studies from other sub-Sahara countries such as Sudan (11.7\%) [22]; Nigeria (7.9\%) [23] and Uganda (16.9\%) [24]. Similarly, HCV prevalence in this study is lower than a previous study in Ghana and reports from elsewhere ranging from 1 to 43.4\% [21-25]. These HBV and or HCV seroprevalence patterns are not different from previous studies from Ghana that involved the general population (i.e. HIV uninfected individuals) where the seroprevalences in most cases ranged from 6.94 to $15.8 \%$ for $\mathrm{HBsAg}$ and 1.84 to $8.4 \%$ for HCV $[14-17,19]$. Only two studies reported lower seroprevalences, $5.5 \%$ for $\mathrm{HBsAg}[18]$ and $0.4 \%$ for $\mathrm{HCV}$ [16]. Comparing the HBV and HCV results of this current study to previous reports of studies conducted in Ghana and other sub-Sahara African countries [22-24, 26] it could be observed that $\mathrm{HBV}$ seroprevalence is higher than $\mathrm{HCV}$ seroprevalence in the Ghanaian population and the sub-Sahara African countries. Thus, it is important to screen all HIV infected individuals in sub-Sahara countries for HBsAg prior to ART.

To the best of our knowledge based on literature review, this is the first study to evaluate the HBV and HCV status of the PLHIV in the Central Region of Ghana. It was found that majority $(92.1 \%)$ of the participants had no information on their HIV-HBV co-infection status and this was not different from HIV-HCV status where none of the 394 participants knew his/her status. This finding confirms that many PLHIV in most developing countries particularly sub-Sahara African countries do not know their co-infection status [27]. This might be due to the fact that the test is not free of charge. Hence testing is optional for the individuals and this may have a negative effect on their life expectancy since HBV and HCV are associated with serious complications such as cirrhosis and hepatocellular carcinoma which in turn increases mortality among PLHIV.

Additionally, we could not perform statistical tests for association for the $\mathrm{HCV}$ positivity and the variables because very few, two persons were co-infected with HCV. Statistical analysis of HIV- HBV co-infection did not show significant association in the HBV infection rate in all the socio-demographic data of the participants (in age groups, gender, educational status, employment, marital status and residence). This result is partly consistent with the findings of Sagoe et al. (2012), who reported that HBV infection among HIV infected persons recruited from Greater Accra Region of Ghana was not associated with age or gender [28]. Kye-Duodu et al. (2016) also found no significant association in HBV infection among PLHIV from rural and urban areas in the Eastern Region of Ghana but in the same study, HBV infection was found to be significantly higher in adults ( $\geq 18$ years). In the Ghanaian general population, HBV infection was reported to be significantly higher in men than women [16] which is contrary to the result of this study. A study from Rwanda also found discordant relationship where older age was associated with HBV infection, but gender was not associated with infection [29]. Our finding also differs from a report from Cameroon where $\mathrm{HBsAg}$ positivity was found to be higher among those living in urban areas than those in the rural areas [30]. Outside sub-Sahara Africa, this result on HBV is in accordance with the findings reported in Nepal [31]. These discrepancies could be due to several factors like differences in the population, geographical areas and differences in infrastructure.

Nevertheless, significant association was seen in the HBV positive rate among WHO clinical stages. Generally, 
Table 3 The demographic and clinical characteristics of the participants in relation to HBV and HCV infection

\begin{tabular}{|c|c|c|c|c|}
\hline Variables & N (\%) & Seroprevalence of HBV coinfection (\%) & $P$ value & Seroprevalence of HCV coinfection (\%) \\
\hline \multicolumn{5}{|l|}{ Age (years) } \\
\hline$\leq 19$ & $12(3.1)$ & $0(0.0)$ & 0.464 & $0(0.0)$ \\
\hline $20-29$ & $44(11.2)$ & $1(2.3)$ & & $0(0.0)$ \\
\hline $30-39$ & $118(30.0)$ & $11(9.3)$ & & $1(0.9)$ \\
\hline $40-49$ & $125(31.7)$ & $8(6.4)$ & & $1(0.8)$ \\
\hline $50-59$ & $71(18.0)$ & $3(4.2)$ & & $0(0.0)$ \\
\hline$\geq 60$ & $24(6.1)$ & $1((4.2)$ & & $0(0.0)$ \\
\hline \multicolumn{5}{|l|}{ Gender } \\
\hline Male & $96(24.4)$ & $5(5.2)$ & 0.809 & $0(0.0)$ \\
\hline Female & $298(75.6)$ & $19(6.4)$ & & $2(0.7)$ \\
\hline \multicolumn{5}{|l|}{ Educational status } \\
\hline None & $77(19.5)$ & $5(6.5)$ & 0.903 & $1(1.3)$ \\
\hline Basic & $257(65.2)$ & $17(6.6)$ & & $0(0.0)$ \\
\hline Secondary & $42(10.7)$ & $2(4.8)$ & & $1(2.4)$ \\
\hline Tertiary & $18(5.6)$ & $0(0.0)$ & & $0(0.0)$ \\
\hline \multicolumn{5}{|l|}{ Employment } \\
\hline Unemployed & $63(16.0)$ & $3(4.7)$ & 0.188 & $1(1.6)$ \\
\hline Informal & $300(76.1)$ & $20(6.7)$ & & $1(0.3)$ \\
\hline Formal & $31(7.9)$ & $1(3.2)$ & & $0(0.0)$ \\
\hline \multicolumn{5}{|l|}{ Marital status } \\
\hline Single & $63(16.0)$ & $2(3.2)$ & 0.240 & $0(0.0)$ \\
\hline Married/Cohabiting & $218(55.3)$ & $16(7.3)$ & & $2(0.9)$ \\
\hline Widow/widower & $53(13.5)$ & $1(1.9)$ & & $0(0.0)$ \\
\hline Divorced & $60(15.2)$ & $5(8.3)$ & & $0(0.0)$ \\
\hline \multicolumn{5}{|l|}{ Residence } \\
\hline Rural & $266(67.5)$ & $17(6.4)$ & 1.000 & $2(0.8)$ \\
\hline Urban & $128(32.5)$ & $7(5.5)$ & & $0(0.0)$ \\
\hline \multicolumn{5}{|l|}{ HIV patients } \\
\hline Newly confirmed cases & 47 (11.9) & $1(2.1)$ & 0.376 & $0(0.0)$ \\
\hline Old cases & $347(88.1)$ & $23(6.6)$ & & $2(0.6)$ \\
\hline \multicolumn{5}{|l|}{ WHO clinical stage } \\
\hline Stage 1 & $271(68.8)$ & $10(3.7)$ & 0.004 & $0(0.0)$ \\
\hline Stage 2 & 78 (19.8) & $12(15.4)$ & & $1(1.3)$ \\
\hline Stage 3 & $29(7.4)$ & $2(6.9)$ & & $0(0.0)$ \\
\hline Stage 4 & $16(4.1)$ & $0(0.0)$ & & $1(6.3)$ \\
\hline \multicolumn{5}{|c|}{$\mathrm{HBV} / \mathrm{HCV}$ status after testing in this study } \\
\hline HBV & 394 & $19 / 394(5.3)^{\mathrm{a}} ; 5 / 394(1.27)^{\mathrm{b}}$ & & \\
\hline $\mathrm{HCV}$ & $394(100)$ & & & $2(0.5)$ \\
\hline Total hepatitis seroprevalence & $26(6.6)$ & $24(6.1)$ & & $2(0.5)$ \\
\hline
\end{tabular}

\footnotetext{
$\mathrm{a}=$ new $\mathrm{HBV}$ positive case detected in this study
}

${ }^{b}=$ Old HBV positive case who tested positive too when tested again in this study

$P$ value in bold indicates variable with evidence of association 
the infection rates were significantly higher in participants at WHO clinical stages 2 and 3. From the literatures reviewed no study from Ghana was found to have reported a result relating to this aspect of our study. Rusine et al. (2013) from Rwanda reported similar finding where HBV infection was also found to be significantly higher in patients at WHO clinical stages 3 or 4 compared to stage 1 [29]. This study also showed no significant association of HBV positivity in old HIV and new HIV infected patients. The major limitation of this study was that the viral DNA and markers of liver-related diseases such as aspartate aminotransferase (AST) and alanine aminotransferase (ALT) could not be determined as well as the CD4 counts of the patients at the various $\mathrm{WHO}$ clinical stages due to limited resources.

\section{Conclusions}

HBV and HCV were detected among the HIV-infected participants. Extremely high proportion had no information on their HBV status, and none had any information on his or her co-infection status before screening in this study. This study recommends the need for policy makers to provide free HBV and HCV screening for all HIV infected individuals for clinician to provide effective management to them including optimal selection of treatment especially for newly diagnosed HIV patients and also in case of switching an individual from first-line ART to second-line ART due to treatment failure. The authors further recommend that the possibility of HBV infected persons rapidly progressing to AIDs stage be investigated.

\section{Abbreviations \\ AIDS: Acquired Immunodeficiency syndrome; ALT: Alanine aminotransferase; APRI: Aminotransferase/platelet ratio index; ART: Antiretroviral therapy; AST: Aspartate aminotransferase; CCMH: Cape Coast Metropolitan Hospital; CCTH: Cape Coast Teaching Hospital; CD4: Cluster of Differentiation; \\ DNA: Deoxyribonucleic acid; HBeAg: Hepatitis B e antigen; HBsAg: Hepatitis B surface antigen; HBV: Hepatitis B virus; HCV: Hepatitis C virus; HIV: Human Immunodeficiency Virus; PLHIV: People Living with HIV; SMH: Saltpond Municipal Hospital; STIs: Sexually transmitted infections; TDF: Tenofovir disoproxil fumarate; UCC: University of Cape Coast; WHO: World Health Organization}

\section{Acknowledgements}

We thank the HIV infected individuals who participated in this study and the staff at the various hospitals for their cooperation and support during data collection.

\section{Ethics approval and consent to participate}

This study was approved by the Institutional Review Board of University of Cape Coast (IRB-UCC), Ghana. Permission was obtained from the authorities of the various hospital before commencement of the study. The purpose and procedures of the study were explained to all participants, and a written informed consent was obtained from all participants, authenticated by signing or thumb printing. A written informed consent was obtained from parents or guardians for child participants.

\section{Funding}

The authors co-funded the research. The financial contribution made by the authors did not play any role in the design of the study, analysis, and interpretation of data and in the writing of the manuscript.

\section{Availability of data and materials}

The datasets used and/or analyzed during this current study are available from the corresponding author on reasonable request.

\section{Authors' contributions}

PF conceived and designed the study, developed the proposal and drafted the manuscript. PF, HOCK and OYD participated in patient's recruitment and data collection at the ART clinics. PF and NP performed the laboratory work and involved in acquisition of literature. PF, HOCK, OYD and NP participated in data analysis and interpretation and critically revised the manuscript. All authors have read and approved the final manuscript.

\section{Consent for publication}

Not applicable

\section{Competing interests}

The authors declare that they have no competing interests.

\section{Publisher's Note}

Springer Nature remains neutral with regard to jurisdictional claims in published maps and institutional affiliations.

\section{Author details}

'Department of Microbiology and Immunology, School of Medical Sciences, College of Health and Allied Sciences, University of Cape Coast, Cape Coast, Ghana. ${ }^{2}$ Department of Medical Biochemistry, School of Medical Sciences, College of Health and Allied Sciences, University of Cape Coast, Cape Coast, Ghana. ${ }^{3}$ Department of Chemical Pathology, School of Medical Sciences, College of Health and Allied Sciences, University of Cape Coast, Cape Coast, Ghana.

Received: 21 January 2019 Accepted: 25 April 2019

Published online: 03 May 2019

\section{References}

1. UNAIDS, 2017 Global HIV statistics. 2018: Fact sheets. http://www.unaids. org/sites/default/files/media_asset/UNAIDS_FactSheet_en.pdf. Accessed 12 Aug 2018.

2. WHO. Global hepatitis report. Licence: cc by -NC-SA 3.0IGO. Geneva: WHO; 2017. p. 2017.

3. Obiri-Yeboah D, et al. Immunologic and virological response to ART among HIV infected individuals at a tertiary hospital in Ghana. BMC Infect Dis. 2018;18(1):230.

4. Farahani $\mathrm{M}$, et al. Prevalence and distribution of non-AIDS causes of death among HIV-infected individuals receiving antiretroviral therapy: a systematic review and meta-analysis. Int J STD AIDS. 2017;28(7):636-50.

5. Ferreira-Junior ODC, et al. Prevalence estimates of HIV, syphilis, hepatitis B and C among female sex workers (FSW) in Brazil, 2016. Medicine (Baltimore). 2018;97(1S Suppl 1):S3-8.

6. Alter MJ. Epidemiology of viral hepatitis and HIV co-infection. J Hepatol. 2006;44(1 Suppl):S6-9.

7. Platt $L$, et al. Prevalence and burden of HCV co-infection in people living with HIV: a global systematic review and meta-analysis. Lancet Infect Dis. 2016;16(7):797-808.

8. Dervisevic S, Pillay D. Issues in diagnostic testing and monitoring in HIV/viral hepatitis co-infection. J HIV Ther. 2003;8(4):89-95.

9. Chun HM, et al. Hepatitis B virus coinfection negatively impacts HIV outcomes in HIV seroconverters. J Infect Dis. 2012;205(2):185-93.

10. WHO. Consolidated guidelines on the use of antiretroviral drugs for treating and preventing Hiv infection. Geneva: Recommendations for a Public Health Approach; 2016.

11. WHO. Guidelines for the screening, care and treatment of persons with chronic hepatitis C infection. Geneva; 2016.

12. Stockdale AJ, et al. Liver fibrosis by transient Elastography and Virologic outcomes after introduction of Tenofovir in lamivudine-experienced adults with HIV and hepatitis B virus coinfection in Ghana. Clin Infect Dis. 2015;61 (6):883-91.

13. Commission GA. Ghana national HIV and AIDS strategic plan 2016-2020. Accra: GAC; 2016.

14. Martinson FE, et al. Seroepidemiological survey of hepatitis $B$ and $C$ virus infections in Ghanaian children. J Med Virol. 1996;48(3):278-83. 
15. Ampofo W, et al. Prevalence of blood-borne infectious diseases in blood donors in Ghana. J Clin Microbiol. 2002;40(9):3523-5.

16. Yakass MB, et al. Prevalence of blood borne viruses in IVF: an audit of a fertility Centre. JBRA Assist Reprod. 2016;20(3):132-6.

17. Ephraim $R$, et al. Seroprevalence and risk factors of hepatitis $B$ and hepatitis $C$ infections among pregnant women in the Asante Akim north municipality of the Ashanti region, Ghana; a cross sectional study. Afr Health Sci. 2015;15(3):709-13.

18. Ephraim $R$, et al. Seroprevalence of hepatitis $B$ and $C$ viral infections among type 2 diabetics: a cross-sectional study in the Cape Coast Metropolis. Ann Med Health Sci Res. 2014;4(5):719-22.

19. Lokpo SY, et al. Viral hepatitis Endemicity and trends among an asymptomatic adult population in ho: a 5-year retrospective study at the ho municipal hospital, Ghana. Hepat Res Treat. 2017;2017:6174743.

20. Agyeman AA, Ofori-Asenso R. Prevalence of HIV and hepatitis B coinfection in Ghana: a systematic review and meta-analysis. AIDS Res Ther. 2016;13:23.

21. King $S$, et al. Antibody screening tests variably overestimate the prevalence of hepatitis C virus infection among HIV-infected adults in Ghana. J Viral Hepat. 2015;22(5):461-8.

22. Mudawi $\mathrm{H}$, et al. Overt and occult hepatitis B virus infection in adult Sudanese HIV patients. Int J Infect Dis. 2014;29:65-70.

23. Tremeau-Bravard A, et al. Seroprevalence of hepatitis B and C infection among the HIV-positive population in Abuja, Nigeria. Afr Health Sci. 2012;12(3):312-7.

24. Baseke J, Musenero M, Mayanja-Kizza H. Prevalence of hepatitis B and C and relationship to liver damage in HIV infected patients attending joint clinical research Centre clinic (JCRC), Kampala, Uganda. Afr Health Sci. 2015;15(2): 322-7.

25. Li CW, et al. Changing seroprevalence of hepatitis $C$ virus infection among HIV-positive patients in Taiwan. PLoS One. 2018;13(3):e0194149.

26. Barth $\mathrm{RE}$, et al. Hepatitis $\mathrm{B} / \mathrm{C}$ and HIV in sub-Saharan Africa: an association between highly prevalent infectious diseases. A systematic review and meta-analysis. Int J Infect Dis. 2010;14(12):e1024-31.

27. Coffie PA, et al. Trends in hepatitis B virus testing practices and management in HIV clinics across sub-Saharan Africa. BMC Infect Dis. 2017;17(Suppl 1):706.

28. Sagoe KW, et al. Prevalence and impact of hepatitis B and C virus coinfections in antiretroviral treatment naive patients with HIV infection at a major treatment center in Ghana. J Med Virol. 2012;84(1):6-10.

29. Rusine J, et al. High seroprevalence of HBV and HCV infection in HIVinfected adults in Kigali, Rwanda. PLoS One. 2013;8(5):e63303.

30. Noubiap JJ, et al. Hepatitis B and C co-infections in some HIV-positive populations in Cameroon, west Central Africa: analysis of samples collected over more than a decade. PLoS One. 2015;10(9):e0137375.

31. Bhattarai $\mathrm{M}$, et al. Epidemiological profile and risk factors for acquiring HBV and/or HCV in HIV-infected population groups in Nepal. Biomed Res Int. 2018;2018:9241679.

Ready to submit your research? Choose BMC and benefit from:

- fast, convenient online submission

- thorough peer review by experienced researchers in your field

- rapid publication on acceptance

- support for research data, including large and complex data types

- gold Open Access which fosters wider collaboration and increased citations

- maximum visibility for your research: over $100 \mathrm{M}$ website views per year

At $\mathrm{BMC}$, research is always in progress.

Learn more biomedcentral.com/submissions 